\title{
Blood level of adipokines and nutritional status variables in adolescent pregnancy
}

Mirela Douradinho Fernandes, MSc, Silvia Daher, PhD, Luciana Moraes de Sousa, BSc, Indiomara Baratto, PhD, Thalita Frutuoso Lobo, PhD, Edward Araujo Júnior, PhD, Cristina Aparecida Falbo Guazzelli, PhD

Department of Obstetrics, Paulista School of Medicine - Federal University of São Paulo (EPM-UNIFESP), São Paulo-SP, Brazil

\section{Objective}

To evaluate the serum levels of adiponectin and leptin and their relationship with nutritional variables during pregnancy in adolescents.

\section{Methods}

This prospective cohort study evaluated eutrophic pregnant adolescents (body mass index [BMI], 18.5-24.9 kg/ $\mathrm{m}^{2}$ ) during the 3 gestational trimesters (first, 10-14 weeks; second, 24-28 weeks; and third, 30-34 weeks). Serum adiponectin and leptin concentrations were measured using the enzyme-linked immunosorbent assay method. The relationship of these adipokines with the pre-gestational BMI, gestational weight gain, weight at the time of sample collection, and newborn weight were evaluated. Analysis of variance and the Kruskal-Wallis test were used for statistical analysis.

Results

The study group comprised 62 pregnant adolescents. The serum concentration of adiponectin showed a significant difference between the first and third trimesters $(P=0.003)$, which decreased during pregnancy, but unrelated to nutritional variables. Serum leptin levels increased throughout the pregnancy $(P<0.0001)$ and showed a positive correlation with pre-gestational BMI, total weight gain, pregnancy weight at the time of sample collection, and newborns' weight.

\section{Conclusion}

Serum levels of adiponectin and leptin vary inversely throughout pregnancy. This pattern in adolescents is similar to that observed in adults. Moreover, leptin concentrations increased throughout pregnancy, and they were positively correlated with all variables evaluated.

Keywords: Adiponectin; Leptin; Nutrition status; Pregnancy; Adolescents

\section{Introduction}

Adolescent pregnancy is highly prevalent in the world despite the development level of the country [1]. The annual report published in 2013 by the United Nations Population Fund (UNFPA) on the situation of the world population cited that yearly, in developing countries, 7.3 million adolescent old have children, of which about 2 million were less than 14 years old [2].

During the gestational period, an inflammatory response develops in the maternal-fetal unit. Several mediators are involved in this process, which includes adipokines. These proteins' participation in local and systemic inflammatory
Received: 2020.04.16. Revised: 2020.07.10. Accepted: 2020.07.15. Corresponding author: Edward Araujo Júnior, PhD

Department of Obstetrics, Paulista School of Medicine - Federal University of São Paulo (EPM-UNIFESP), Rua Belchior de Azevedo, 156 apto. 111 Torre Vitoria, São Paulo-SP, CEP 05089030, Brazil

E-mail: araujojred@terra.com.br

https://orcid.org/0000-0002-6145-2532

Articles published in Obstet Gynecol Sci are open-access, distributed under the terms of the Creative Commons Attribution Non-Commercial License (http://creativecommons. org/licenses/by-nc/3.0/) which permits unrestricted non-commercial use, distribution, and reproduction in any medium, provided the original work is properly cited.

Copyright $\odot 2020$ Korean Society of Obstetrics and Gynecology 


\title{
Obstetrics \& Gynecology Science
}

\author{
Vol. 63, No. 6, 2020
}

reactions is recognized, but the influence of adipokines on the evolution of pregnancy is not fully understood yet [3]. Adiponectin has the function of regulating metabolism interfering with insulin resistance (IR) in the liver and muscles [4] besides presenting an anti-inflammatory, anti-hyperglycemic, and anti-atherogenic action [5]. During a healthy pregnancy, adiponectin levels progressively decrease, and IR develops, which returns to pre-pregnancy values after delivery [6]. Leptin works by modulating appetite and controlling levels of adipose tissue in eutrophic individuals. Blood leptin concentrations are high in women and even higher in pregnant women [7]. The placenta secrets leptin, and it has been associated with adverse maternal and perinatal outcomes [8].

Adiponectin and leptin present physiological actions, thus affecting patients' health according to their concentrations in the blood. However, few studies relate these two molecules in the evolution of pregnancy, especially in adolescents. To date, no studies have assessed the relationship between pregestational body mass index (BMI), maternal and newborn weight gain with the concentrations of these adipokines in adolescents. Therefore, this study aimed to assess serum levels of adiponectin and leptin and their relationship with nutritional variables throughout adolescent pregnancy. The results of this study will be useful for future investigations of the association between serum changes in adiponectin or leptin levels and adverse perinatal outcomes, such as miscarriage, pre-eclampsia, diabetes mellitus, preterm birth, fetal growth restriction, low birth weight, and inadequate gestational weight gain, among pregnant adolescents.

\section{Materials and methods}

A prospective cohort study was conducted among eutrophic pregnant adolescents $\left(\mathrm{BMI}, 18.5-24.9 \mathrm{~kg} / \mathrm{m}^{2}\right.$ ) who attended the Adolescent Prenatal Sector of the Federal University of São Paulo (UNIFESP) from March 2015 to January 2017. The Research Ethics Committee from UNIFESP approved this study under the consubstantiated opinion No. 1514/11, and all pregnant women who agreed to participate voluntarily signed an informed consent form. The inclusion criterion was a single pregnancy in adolescents aged $<20$ years. Exclusion criteria were the use of medications (corticosteroids, antibiotics, immunosuppressants, and anti-inflammatories); maternal obstetric or chronic diseases (pre-eclampsia, gestational dia- betes mellitus, chronic arterial hypertension, systemic lupus erythematosus, and asthma); and presence of obstetric complications (e.g., prematurity) at birth.

The BMI was calculated using the formula pre-gestational maternal weight $(\mathrm{kg}) /$ height $\left(\mathrm{m}^{2}\right)$, with the former referred by the mother and the latter confirmed with measurement. The nutritional diagnosis was determined as recommended by the Institute of Medicine (IOM) [9].

Blood collection occurred during the 3 periods of pregnancy: first trimester (10 to 14 weeks), second trimester (24 to 28 weeks), and third trimester (30 to 34 weeks). An $8 \mathrm{~mL}$ volume of peripheral blood was collected by venipuncture in a dry tube. The samples were transported in thermal boxes, refrigerated at a temperature between $2^{\circ} \mathrm{C}$ and $8^{\circ} \mathrm{C}$ and processed within a maximum period of up to 4 hours after collection. The blood samples were centrifuged after clot retraction at $500 \mathrm{rpm}$ for 15 minutes at room temperature. The serum obtained was aliquoted in sterile and dry microtubes and then stored at $-80^{\circ} \mathrm{C}$ for future quantification of adiponectin and leptin serum concentrations.

Serum levels of adiponectin and leptin were assessed using the enzyme-linked immunosorbent assay (ELISA) method using the commercial kit Quantikine ${ }^{\circledR}$-Human total Adiponectin/Acrp30 DuoSet (R\&D Systems ${ }^{\circledR}$, Minneapolis, MN, USA) and Quantikine ${ }^{\circledR}$ Human Leptin DuoSet (R\&D Systems ${ }^{\circledR}$ ). These kits are immunoenzymatic ELISA tests, which were performed according to the manufacturer's instructions. The test sensitivity was $0.0625 \mathrm{ng} / \mathrm{mL}$ for adiponectin and 32.25 $\mathrm{pg} / \mathrm{mL}$ for leptin. The intra-assay and inter-assay CVs\% for adiponectin were $3.5 \%$ and $6.5 \%$ and for leptin 3.2\% and $4.4 \%$, respectively.

For adiponectin and leptin dosage curves in pregnant adolescents in the first, second, and third trimester, tables containing minimum, maximum, mean, or median values and standard deviation (SD) or interquartile range were included. Normality tests such as Skewness and Kurtosis, KolmogorovSmirnov, and Shapiro-Wilk, were applied to assess the distribution of quantitative variables. Thus, analysis of variance (ANOVA) was applied for parametric distributions and the Kruskal-Wallis test for nonparametric distributions, followed by Tukey or Dunn post-tests, respectively. Pearson's coefficient ( $r$ ) was used to assess the correlation between variables. Descriptive statistics were performed with minimum and maximum values, mean and SD for maternal age, BMI, and race. The level of statistical significance was established 


\section{Obstetrics \& Gynecology Science}

Mirela Douradinho Fernandes, et al. Blood level of adipokines in adolescents

at $P<0.05$. Statistical analyzes were performed using the GraphPad Prism software version 6.0 (GraphPad Software, San Diego, CA, USA).

\section{Results}

In this study, 62 eutrophic pregnant adolescents were included and evaluated in the three trimesters of pregnancy. Maternal age ranged from 12 to 19 years, with an average of $16.45 \pm 1.87$ years. The mean of the pre-gestational BMI was $21.8 \pm 2.23 \mathrm{~kg} / \mathrm{m}^{2}$. The average gestational age in the first, second, and third trimesters was 12.38 $1.35,25.36 \pm 2.62$, and $32.90 \pm 2.42$ weeks, respectively (Table 1).

We observed significant difference between the adiponectin values obtained in the first, second, and third trimesters. As pregnancy progressed, serum adiponectin levels gradually decreased (median 3,578 ng/mL, 2,774 ng/mL, 2,218 ng/ $\mathrm{mL}$, respectively). In Dunn post-tests, a statistically significant difference was observed when comparing the first and third trimesters $(P=0.003)$. However, no statistically significant difference was found comparing the first and second trimesters and the second and third trimesters $(P=0.09$ and $P=0.82$, respectively) (Table 2 ).

Table 1. Maternal and perinatal characteristics of pregnant adolescents

\begin{tabular}{|c|c|c|c|}
\hline Characteristic & $1^{\text {st }}$ trimester $(n=62)$ & $2^{\text {nd }}$ trimester $(n=62)$ & $3^{\text {rd }}$ trimester $(n=62)$ \\
\hline \multicolumn{4}{|l|}{ Age (yr) } \\
\hline Minimum-Maximum & & $12-19$ & \\
\hline Mean \pm SD & & $16.45 \pm 1.87$ & \\
\hline \multicolumn{4}{|l|}{$\operatorname{BMl}\left(\mathrm{kg} / \mathrm{m}^{2}\right)$} \\
\hline Minimum-Maximum & & $18.5-24.9$ & \\
\hline Mean $\pm S D$ & & $21.80 \pm 2.23$ & \\
\hline \multicolumn{4}{|l|}{ Race/ethnicity } \\
\hline White & & $36(58.06 \%)$ & \\
\hline Mixed & & $26(41.94 \%)$ & \\
\hline \multicolumn{4}{|l|}{ Total weight gain (kg) } \\
\hline Minimum-Maximum & & $6.50-30.00$ & \\
\hline Mean $\pm S D$ & & $13.60 \pm 4.56$ & \\
\hline \multicolumn{4}{|l|}{ Newborn weight (g) } \\
\hline Minimum-Maximum & & $2,115-4,200$ & \\
\hline Mean $\pm S D$ & & $3,064.80+484.43$ & \\
\hline \multicolumn{4}{|c|}{ Gestational age at sample collection (wk) } \\
\hline Minimum-Maximum & $10.00-14.11$ & $24.10-28.20$ & $30.43-34.10$ \\
\hline Mean \pm SD & $12.38 \pm 1.35$ & $25.36 \pm 2.62$ & $32.90 \pm 2.42$ \\
\hline
\end{tabular}

BMI, body mass index; GA, gestational age; SD, standard deviation.

Table 2. Serum adiponectin and leptin concentrations in the three trimesters of adolescent pregnancies

\begin{tabular}{|c|c|c|c|c|c|c|c|}
\hline \multirow{2}{*}{$\begin{array}{l}\text { Trimester } \\
(n=62)\end{array}$} & \multicolumn{4}{|c|}{ Adiponectin (ng/mL) } & \multicolumn{3}{|c|}{ Leptin $(p g / m L)$} \\
\hline & Min-Max & Median & Interquartile range & $P^{\text {a) }}$ & Min-Max & Mean \pm SD & $P^{b)}$ \\
\hline $1^{\text {st }}$ & $1,141-13,499$ & 3,578 & $2,388-5,952$ & 0.09 & $5,594-166,097$ & $36,807 \pm 31,946$ & 0.26 \\
\hline $2^{\text {nd }}$ & $1,205-16,035$ & 2,774 & $1,578-4,336$ & 0.003 & $1,401-96,912$ & $27,983 \pm 18,755$ & 0.005 \\
\hline $3^{\text {rd }}$ & $1,428-13,857$ & 2,218 & $1,727-3,615$ & 0.82 & $3,997-189,830$ & $54,435 \pm 39,226$ & $<0.0001$ \\
\hline \multicolumn{5}{|c|}{ Kruskal-Wallis test, $P=0.003$} & \multicolumn{3}{|c|}{ One-way ANOVA, $P<0.0001$} \\
\hline
\end{tabular}

$\mathrm{SD}$, standard deviation; ANOVA, analysis of variance.

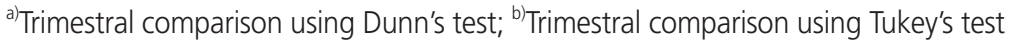




\section{Obstetrics \& Gynecology Science}

Vol. 63, No. 6, 2020

We did not observe any correlation between serum adiponectin levels and pre-pregnancy BMI, total pregnancy weight gain, maternal weight at the time of blood collection, and newborn weight (data not shown).

Serum leptin concentrations decreased in the second trimester; however, with the progression of pregnancy, there was a significant increase in blood levels $(P<0.0001)$. In the third trimester, serum leptin levels were higher (mean, $54,435 \pm 39,226 \mathrm{pg} / \mathrm{mL}$ ) when compared to the first (mean, $36,807 \pm 31,946 \mathrm{pg} / \mathrm{mL})(P=0.005)$ and the second trimesters (mean, 27,983 $\pm 18,755 \mathrm{pg} / \mathrm{mL})(P<0.0001)$, when the Turkey's post-tests was performed (Table 2 ).

We observed a positive correlation between serum leptin levels and pre-pregnancy BMI, total weight gain during pregnancy, maternal weight at the time of blood collection, and newborn weight (Table 3).

\section{Discussion}

In general, the vast majority of studies on adipokines are restricted to comparing the serum profile among pregnant adults with and without obstetric complications or associated diseases [10-12]. Adipokines have been the subject of studies that seek to find and determine biomarkers to assist in prevention or prognosis of complications such as pre-eclampsia, gestational diabetes mellitus, restriction of intrauterine growth, and low birth weight $[13,14]$.

In this study, serum adiponectin levels in pregnant adolescents decreased progressively throughout pregnancy. This result was also observed in adult women during healthy pregnancies $[15,16]$. A possible explanation would be due to the installation and/or change of $I R$, which tends to increase with the evolution of pregnancy and returns to pre-pregnancy values after delivery $[17,18]$. Thus, we found a negative correlation between gestational age and serum adiponectin concentration, which is also described in the literatures including other age groups $[19,20]$.

Fuglsang et al. [21] compared the first with the third trimester of pregnancy and observed that plasma levels of adiponectin in adult pregnant women significantly decreased. This behavior was also observed in this study in pregnant adolescents and confirmed by other studies in pregnant women $[22,23]$.

Table 3. Correlation between pre-gestational body mass index, total weight gain during pregnancy, weight at the time of blood collection and newborn weight, and serum leptin levels between the first, second, and third trimester of adolescent pregnancy

\begin{tabular}{|c|c|c|c|}
\hline \multirow{2}{*}{ Variable } & \multicolumn{3}{|c|}{ Leptin (pg/mL) } \\
\hline & $1^{\text {st }}$ Trimester $(n=62)$ & $2^{\text {nd }}$ Trimester $(n=62)$ & $3^{\text {rd }}$ Trimester $(n=62)$ \\
\hline \multicolumn{4}{|c|}{ Pre-gestational BMI $\left(\mathrm{kg} / \mathrm{m}^{2}\right)$} \\
\hline Pearson $r$ & 0.44 & 0.51 & 0.27 \\
\hline Confidence interval & $0.21,0.62$ & $0.29,0.67$ & $0.02,0.49$ \\
\hline$P^{a)}$ & $0.0003^{b)}$ & $<0.0001^{b)}$ & $0.03^{b)}$ \\
\hline \multicolumn{4}{|l|}{ Total weight gain (kg) } \\
\hline Pearson r & 0.22 & 0.26 & 0.32 \\
\hline Confidence interval & $-0.02,0.44$ & $0.01,0.48$ & $0.07,0.52$ \\
\hline$P^{a)}$ & 0.08 & $0.04^{b)}$ & $0.01^{\mathrm{b})}$ \\
\hline \multicolumn{4}{|c|}{ Weight at sample collection (kg) } \\
\hline Pearson $r$ & 0.40 & 0.42 & 0.39 \\
\hline Confidence interval & $0.17,0.59$ & $0.19,0.61$ & $0.15,0.58$ \\
\hline$P^{a)}$ & $0.001^{b)}$ & $0.0007^{b)}$ & $0.001^{b)}$ \\
\hline \multicolumn{4}{|l|}{ Newborn weight (g) } \\
\hline Pearson $r$ & 0.25 & 0.32 & 0.09 \\
\hline Confidence interval & $0.003,0.47$ & $0.07,0.53$ & $-0.15,0.33$ \\
\hline$P^{\mathrm{a})}$ & $0.04^{\mathrm{b})}$ & $0.01^{\mathrm{b})}$ & 0.44 \\
\hline
\end{tabular}

${ }^{\text {a) }}$ Pearson's correlation coefficient; ${ }^{\text {b) }} P<0.05$. 


\section{Obstetrics \& Gynecology Science}

Mirela Douradinho Fernandes, et al. Blood level of adipokines in adolescents

In the second trimester, we observed a significant decrease in serum adiponectin concentrations, which may be related to the installation of IR, which occurs mainly during this period. Some studies correlated the concentration of adiponectin with IR indexes during pregnancy in adult women $[24,25]$.

When assessing serum leptin levels, we observed significantly increased values from the first to the third trimester of pregnancy in adolescents. This result can also be observed in other studies involving pregnant women and adolescents with a methodology similar to ours $[26,27]$.

Duarte et al. [28] studied serum leptin levels in the second and third trimesters of pregnant adolescents with and without pre-eclampsia, identifying a non-significant increase in this hormone between 21 and 30 weeks in both groups. They demonstrated that leptin concentrations tended to be higher in the last trimester of pregnancy with the presence of pre-eclampsia. Jones et al. [29] analyzed serum leptin concentrations between 28 and 32 weeks of pregnancy, dividing the adolescents into early (14 and 15 years) and late (16 to 18 years), and reduced leptin concentrations was observed only in the group of late teenagers.

We observed positive correlation between pre-pregnancy BMI and serum leptin levels. Thus, these results confirm the findings of a previous study that evaluated pregnant adolescents and young adults, in which those who had a higher concentration of leptin also had a higher pre-pregnancy BMI value and a lower level of adiponectin [30].

The higher concentrations of leptin that occur during pregnancy are related to weight gain, as well as changes in hormonal levels, which can stimulate leptin secretion [31]. We have identified a positive correlation between weight gain during pregnancy and serum leptin concentration in all trimesters of pregnancy.

In this study, the slight decline in serum leptin levels at second trimester was also attributed to the development of IR, which occurs during this period, as observed in other studies $[11,27]$.

In a study conducted among 61 adult pregnant women, the authors observed that high serum leptin levels were found in those who gave birth to newborns with higher weight [30]. Similarly, in this study, a positive correlation was also observed between serum leptin concentration of pregnant adolescents and higher birth weight.

In summary, we observed that serum adiponectin levels in pregnant adolescents decreased throughout pregnancy; however, pregnancy leptin levels increased, and they were positively correlated with all variables evaluated. Additionally, one of the strengths of this study was its originality. Our study had, as its main positive point, the prospective monitoring of serum concentrations of adiponectin and leptin during the pregnancy of adolescents, evaluating the same adolescent in all trimesters. Thus, this study was able to have more precise view of the molecules' behavior in the blood during this period, which can be used in the future to manufacture new biomarkers in order to prevent adverse perinatal outcomes, considering that this population is naturally classified as high risk.

In addition, we could not report some correlations of other variables related to maternal, neonatal body composition and leptin levels in the adolescent population, which is still little known.

\section{Conflict of interest}

No potential conflict of interest relevant to this article was reported.

\section{Ethical approval}

The study was approved by the Adolescent Prenatal Sector of the Federal University of São Paulo (UNIFESP) (No. 1514/11) and performed in accordance with the principles of the Declaration of Helsinki. Written informed consents were obtained.

\section{Patient consent}

The patients provided written informed consent for the publication and the use of their images.

\section{References}

1. Chedraui P. Pregnancy among young adolescents: trends, risk factors and maternal-perinatal outcome. J Perinat Med 2008;36:256-9.

2. Fundo de População das Nações Unidas. State of world 


\section{Obstetrics \& Gynecology Science}

Vol. 63, No. 6, 2020

population 2013. Motherhood in childhood: facing the challenge of adolescent pregnancy [Internet]. New York (NY): United Nations Population Fund; 2013 [cited 2016 Feb 18]. Available from: http://www.unfpa.org/publications/state-world-population-2013.

3. Moulin CM, Marguti I, Peron JP, Rizzo LV, Halpern A. Impact of adiposity on immunological parameters. Arq Bras Endocrinol Metabol 2009;53:183-9.

4. Mazaki-Tovi S, Romero R, Vaisbuch E, Erez O, Mittal P, Chaiworapongsa $T$, et al. Maternal serum adiponectin multimers in gestational diabetes. J Perinat Med 2009;37:637-50.

5. Low CF, Mohd Tohit ER, Chong PP, Idris F. Adiponectin SNP45TG is associated with gestational diabetes mellitus. Arch Gynecol Obstet 2011;283:1255-60.

6. Yadav A, Kataria MA, Saini V, Yadav A. Role of leptin and adiponectin in insulin resistance. Clin Chim Acta 2013;417:80-4.

7. Henson MC, Castracane VD. Leptin in pregnancy: an update. Biol Reprod 2006;74:218-29.

8. Vernini JM, Moreli JB, Costa RA, Negrato CA, Rudge MV, Calderon IM. Maternal adipokines and insulin as biomarkers of pregnancies complicated by overweight and obesity. Diabetol Metab Syndr 2016;8:68.

9. Institute of Medicine. Weight gain during pregnancy: reexaminig the guidelines. Washington, D.C.: The National Academies Press; 2009.

10. Lage M, Garcia-Mayor RV, Tomé MA, Cordido F, Valle-Inclan F, Considine RV, et al. Serum leptin levels in women throughout pregnancy and the postpartum period and in women suffering spontaneous abortion. Clin Endocrinol (Oxf) 1999;50:211-6.

11. Al-Atawi FS, Addar MH, Warsy AS, Babay ZA. Leptin concentration during different trimesters of pregnancy and its relation to other pregnancy hormones. Saudi Med J 2004;25:1617-22.

12. Tommaselli GA, Di Spiezio Sardo A, Di Carlo C, Bifulco G, Cerrota G, Cirillo D, et al. Do serum leptin levels have a role in the prediction of pregnancy outcome in case of threatened miscarriage? Clin Endocrinol (Oxf) 2006;65:772-5.

13. Georgiou HM, Lappas M, Georgiou GM, Marita A, Bryant VJ, Hiscock R, et al. Screening for biomarkers predictive of gestational diabetes mellitus. Acta Diabetol 2008;45:157-65.
14. Valle M, Gascón F, Martos R, Bermudo F, Ceballos P, Suanes $A$. Relationship between high plasma leptin concentrations and metabolic syndrome in obese pre-pubertal children. Int J Obes Relat Metab Disord 2003;27:13-8.

15. Sagawa N, Yura S, Itoh H, Mise H, Kakui K, Korita D, et al. Role of leptin in pregnancy--a review. Placenta 2002;23 Suppl A:S80-6.

16. Valsamakis G, Kumar S, Creatsas G, Mastorakos G. The effects of adipose tissue and adipocytokines in human pregnancy. Ann N Y Acad Sci 2010;1205:76-81.

17. Ryan EA. Hormones and insulin resistance during pregnancy. Lancet 2003;362:1777-8.

18. Manoharan B, Bobby Z, Dorairajan G, Vinayagam V, Packirisamy RM. Adipokine levels and their association with insulin resistance and fetal outcomes among the newborns of Indian gestational diabetic mothers. Saudi Med J 2019;40:353-9.

19. Nanda S, Savvidou M, Syngelaki A, Akolekar R, Nicolaides $\mathrm{KH}$. Prediction of gestational diabetes mellitus by maternal factors and biomarkers at 11 to 13 weeks. Prenat Diagn 2011;31:135-41.

20. Hara K, Yamauchi T, Kadowaki T. Adiponectin: an adipokine linking adipocytes and type 2 diabetes in humans. Curr Diab Rep 2005;5:136-40.

21. Fuglsang J, Skjaerbaek C, Frystyk J, Flyvbjerg A, Ovesen $P$. A longitudinal study of serum adiponectin during normal pregnancy. BJOG 2006;113:110-3.

22. Vitoratos N, Valsamakis G, Mastorakos G, Boutsiadis A, Salakos N, Kouskouni E, et al. Pre- and early post-partum adiponectin and interleukin-1 beta levels in women with and without gestational diabetes. Hormones (Athens) 2008;7:230-6.

23. Hedderson MM, Darbinian J, Havel PJ, Quesenberry CP, Sridhar S, Ehrlich S, et al. Low prepregnancy adiponectin concentrations are associated with a marked increase in risk for development of gestational diabetes mellitus. Diabetes Care 2013;36:3930-7.

24. López-Bermejo A, Fernández-Real JM, Garrido E, Rovira $R$, Brichs R, Genaró $P$, et al. Maternal soluble tumour necrosis factor receptor type 2 (sTNFR2) and adiponectin are both related to blood pressure during gestation and infant's birthweight. Clin Endocrinol (Oxf) 2004;61:54452.

25. McLachlan KA, O'Neal D, Jenkins A, Alford FP. Do adiponectin, TNFa, leptin and CRP relate to insulin resistance 


\section{Obstetrics \& Gynecology Science}

Mirela Douradinho Fernandes, et al. Blood level of adipokines in adolescents

in pregnancy? Studies in women with and without gestational diabetes, during and after pregnancy. Diabetes Metab Res Rev 2006;22:131-8.

26. Misra VK, Straughen JK, Trudeau S. Maternal serum leptin during pregnancy and infant birth weight: the influence of maternal overweight and obesity. Obesity (Silver Spring) 2013;21:1064-9.

27. Baratto I, Daher S, Lobo TF, Araujo Júnior E, Guazzelli CA. Adiponectin and leptin serum levels in normal adolescent pregnancies. J Matern Fetal Neonatal Med 2019;11:1-6.

28. Duarte AVB, Barroso SG, Francischetti EA, de Abreu VG.
Leptin, additional link to the pathophysiology of preeclampsia? Rev Bras Ginecol Obstet 2001;23:283-7.

29. Jones RL, Cederberg HM, Wheeler SJ, Poston L, Hutchinson CJ, Seed PT, et al. Relationship between maternal growth, infant birthweight and nutrient partitioning in teenage pregnancies. BJOG 2010;117:200-11.

30. Josefson JL, Zeiss DM, Rademaker AW, Metzger BE. Maternal leptin predicts adiposity of the neonate. Horm Res Paediatr 2014;81:13-9.

31. Caprio M, Fabbrini E, Isidori AM, Aversa A, Fabbri A. Leptin in reproduction. Trends Endocrinol Metab 2001;12:65-72. 